\title{
CRÍTICA CIENTÍFICA E MODELOS INTERPRETATIVOS EM NIETZSCHE
}

Roberto BARROS ${ }^{1}$

- RESUMO: A partir da denúncia da contraditória presença de pressupostos morais dogmáticos na formulação dos princípios norteadores da atividade científica, Nietzsche concebe uma outra noção de cientificidade, compatível com a opção hegemônica pelo saber, que ele reconhece como presente na cultura ocidental. O presente artigo visa a discutir sob quais parâmetros Nietzsche, no período intermediário de sua produção filosófica, empreende sua interpretação da cientificidade ocidental e como, apresentando-se como seu fomentador, ele formula uma crítica desmistificadora desta.

- PALAVRAS-CHAVE: ciência; efetividade; realidade; história; moralidade.

Em um fragmento póstumo do início da década de 1880, Nietzsche escreve: "Moralidade, uma invenção asiática. Nós somos dependentes da Ásia" (FP. KSA 9, I [90]). ${ }^{2}$ Esta anotação do outono/inverno de 1881, portanto, do período de redação de Aurora (1881), exprime uma das perspectivas centrais de sua filosofia posterior a seu rompimento intelectual com relação a Richard Wagner, à filosofia de Arthur Schopenhauer e ao idealismo alemão. Aurora marca, por conseguinte, segundo o comentário posterior de seu próprio autor, o início da campanha contra a moral, que deve levar o leitor a despedir-se do livro com "uma reservada cautela diante de tudo o que até agora foi venerado e adorado sob o nome de Moral" (EH/EH/A § 1). Aurora, entretanto, é também o segundo passo de Nietzsche em direção a sua proposta de uma nova perspectiva científica, que o leva não apenas a formular a concepção de uma "Gaia Ciência", como a escrever Assim falava Zaratustra enquanto obra filosófica.

1 Doutor em Filosofia pela Universidade Técnica de Berlim (Alemanha). Professor da Faculdade de Filosofia da Universidade Federal do Pará. Artigo recebido em 05/2008 e aprovado em 08/2008.

2 Todas as referências feitas a escritos de Nietzsche reportam-se à Kritische Studien Ausgabe (KSA), Munique/Berlim, DTV, Walter de Gruyter, 1988. 
Para uma melhor aproximação daquilo que Nietzsche tenciona dizer na passagem acima citada, é necessário um retorno estratégico ao filosofar histórico por ele formulado a partir de Humano, demasiado humano, então relacionado com a ciência natural e anunciado como "o mais novo dos métodos filosóficos" (MAM/HDH I § 1). Este é concebido pelo filósofo enquanto modo de contraposição à metafísica, como forma de evidenciar pressupostos teóricos obsoletos presentes na filosofia e na perspectiva científica moderna desde Sócrates (Haberkamp, 2000, p. 158), e que teria resultado em um afastamento da primeira com relação à vida e ao mundo. Segundo uma interpretação mais aguçada, história significa a oposição a toda tendência que almeje uma compreensão fundamental e definitiva da realidade, ${ }^{3}$ tal

3 Propõe-se aqui, à guisa de uma acentuação do caráter não metafísico da filosofia de Nietzsche, uma diferenciação de significado na utilização dos termos "efetividade" (Wirklichkeit) e "realidade" (Realität) em Nietzsche. O primeiro, mormente utilizado nos primeiros escritos, quando da influência schopenhaueriana sobre o autor, para designar o princípio determinante e subjacente ao mundo. A utilização do termo, entretanto, a nosso ver, altera-se nos escritos subsequentes ao afastamento de Nietzsche da filosofia de seu outrora mestre. Essa mudança evidencia-se nos primeiros aforismos ( $§ 3$ e $\S 5$ ) do segundo volume de Humano, demasiado humano, nos quais, em ordem inversa, podemos constatar a crítica da dicotomia schopenhaueriana entre Vontade e Mundo e a opção do filósofo pretendente (Freier), que, longamente enganado, opta como consolo pela mais feia efetividade, precisamente aquela que por muito tempo recebeu e enganou os melhores (MAM II/HDH II Vermichte Meinungen und Sprüche § 3). Nossa proposta é que Nietzsche refere-se com esta nova acepção do termo prioritariamente a dois fatores: a) à compreensão da acepção idealista da primeira utilização do termo "efetividade" e b) sua compreensão enquanto insuperável impulso humano à representação do mundo, expresso na ativa capacidade metafórica que se manifesta na arte (HDH/MAM II Vermichte Meinungen und Sprüche § 113), no pensamento racional, em suas generalizações e conceitos. Isso significa que, diferentemente da realidade efetiva e indeterminada do mundo, a efetividade à qual os filósofos se referem, na tentativa de designá-la, nada mais é que um produto de nossas avaliações (FP KSA 1125 [434]) e representações. O termo "realidade", por conseguinte, é usado predominantemente, nos últimos textos (conf. GD/CI Die vier grossen Irthümen § 3: "Der irthum Von Geist als Ursache mit der Realität verwechselt"), em sentido não metafísico, para designar o existente em suas manifestações e possibilidades indetermináveis, caracterizadas pelo constante vir-a-ser (idem § 8). Desse modo, a efetividade torna-se um produto da atividade humana e é regida pelo perspectivismo, entendido como atividade interpretativo-representativa do existente, que para Nietzsche é uma atitude inerente e produtora de sentido. Um ponto importante, porém, nesta proposta de interpretação diferenciada dos termos é evitar a aproximação do uso do termo Realität em Nietzsche da acepção metafísica deste (FP KSA 1314 [168]), base da dicotomia entre mundo real e mundo aparente, o que o filósofo decisivamente ambiciona superar (FW/GC § 54). Deve ser mencionada aqui nossa concordância com a tradução do termo Wirklichkeit com base no verbo wirken, efetuada por Rubens Rodrigues Torres Filho para o volume "Nietzsche" da coleção Os Pensadores e referente ao aforismo 58 de A gaia ciência (p. 197), que em muito corrobora o caráter perspectivístico do termo, relacionado com as influências da filosofia idealista alemã (Marques, 2003, p. 57), tal como o que é aqui proposto. Gostaríamos, porém, de propor a compreensão da passagem "Was wäre das für ein Narr, der da meinte, es genüge, auf diesen Ursprung und diese Nebelhülle des Wahns hinzuweisen, um die als wesenhaft geltende Welt, die sogenannte 'Wirklichkeit' zu vernichten! Nur als Schaffende können wir vernichten!", do mesmo aforismo, como percepção da impossibilidade de superação da produção perspectivística de representações do real e do apelo à experimentação representacional criativa que Nietzsche faz à filosofia, tema decisivamente presente no aforismo e que pode também servir de justificativa à diferenciação aqui proposta. 
como se propunha a metafísica. A crítica de Nietzsche à metafísica ocidental dá-se com base na oposição ao princípio de veracidade ontológica, ou seja, é contrária à crença na existência de uma realidade subjacente e estável, enquanto oposto de uma mera manifestação fenomênica mutável, que, portanto, segundo critérios lógicos de consideração da identidade, não possuiria valor ontológico (Heller, 1972, p. 5). Essa nova perspectiva histórica que, entretanto, opondo-se à historicidade do idealismo alemão - entendido como "velada teodiceia cristã" ("verklappte christliche Theodicee". Heller, 1972) -, pretende superar questões unicamente teóricas acerca da possibilidade e pressupostos do conhecimento, pela consideração do caráter humano destas, e não mais buscando fazê-lo meramente por meio de uma discussão lógico-conceitual, que Nietzsche aceita como recurso metodológico próprio da filosofia, mas critica enquanto fonte de verdades em si (MAM/HDH I § 6). Desse modo, a perspectiva histórica é associada à psicologia (MAM/HDH I § 20) e à fisiologia, com as quais ele se volta contra as interpretações tradicionais acerca da relação entre intelecto e instintos, e à antropologia, compreendida como especulação amoral acerca do homem.

Todas estas novas tendências, que Nietzsche então integra a sua filosofia a partir de Humano, demasiado humano, têm como objetivo fundamental formular um novo modelo de investigação científica que, produto da compreensão do caráter humano desta, não possa mais ser circunscrito e delimitado por perspectivas formais ou morais. Neste sentido, enquanto a perspectiva histórica e a antropologia demonstram a proveniência das múltiplas formas de interpretação do homem, e, por conseguinte, a restrição e a relatividade delas no contexto das múltiplas culturas e momentos históricos, cabe à psicologia e à fisiologia demonstrar, com base em uma análise não racionalista, os processos físicos e psíquicos por meio dos quais provieram as formas humanas de consideração. ${ }^{4}$ Olhar a humanidade sob esta perspectiva significa poder escrever o processo de composição, a "química" de seus conceitos e sentimentos (MAM/HDH I § 1), entendida desde então como cambiante representação humana do mundo (Heller, 1972, p. 4), o qual deixa então de possuir uma essência racionalmente acessível.

O objetivo de tal associação é demonstrar que, somente devido à falta de sentido histórico, o defeito hereditário dos filósofos (MAM/HDH I § 2), foi possível que questões metafísicas fossem consideradas, apenas esquemática ou conceitualmente, como questões unicamente cognitivas, e não como representações de perspectivas humanas não necessariamente fundadas em processos racionais indefectíveis. Este ponto de vista decorre da-

4 Neste sentido Wotling menciona a psicologia como "via de acesso privilegiado à experiência do pensar" (conf. Wotling, 1997). 
quilo que Nietzsche interpreta como processo de moralização da cultura, identificado por ele como responsável pela supremacia da perspectiva universalizante da metafísica e da ciência no Ocidente a partir de Sócrates (Figal, 2001, p. 106), e que se perpetua ainda em uma linha de continuidade, liga-se ao desejo de universalidade moral da doutrina cristã, protofenômeno do qual resultam tanto a Revolução Francesa, como o Iluminismo (MAM/ HDH I § 110) e o socialismo (Kang, 2003, p. 18).

A oposição de Nietzsche baseia-se na denúncia da fragilidade científica dessa forma de consideração. Segundo ele, os princípios mobilizados pelo racionalismo metafísico foram determinantes para o distanciamento do mundo e para a superficialidade científica da metafísica. A permanência da utilização desses pressupostos revela-se-lhe como uma perspectiva moral imposta, subjacente a toda metafísica, que por meio dela impossibilita toda atitude verdadeiramente cognitiva diante do mundo e de sua efetividade. Em outras palavras, o que Nietzsche visa com a crítica tanto do racionalismo metafísico como do universalismo moral cristão é, fundamentalmente, denunciar o processo histórico de falsificação e negação da efetividade tal qual ela se apresenta na metafísica em favor de perspectivas moralizantes e sem caráter científico pleno (MAM/HDH I § 34). Apenas com base nisso a real significação da ciência para a cultura pode ser analisada.

Com Humano, demasiado humano, Nietzsche evidencia a nova orientação de sua filosofia e direciona sua diatribe ao significado das concepções metafísicas e religiosas identificadas no domínio dos valores culturais. Seu objetivo é reconsiderar a clássica subordinação da cultura à cientificidade, que em Platão tem seu ponto de partida. O que lhe parece paradoxal, por conseguinte, é o fato de que, em uma cultura que se autodefine como direcionada para o conhecimento (GT/NT § 18) e na qual este deve ser fundado sob o autoconhecimento do próprio homem (Kang, 2003, p. 16), durante séculos foram construídas apenas interpretações moralizantes deste e de suas relações com o mundo, todas elas norteadas por valores preestabalecidos, cujo erro inicial consistiu precisamente em formular uma ideia normativo-corretiva da realidade.

A denúncia da contradição desse procedimento científico no interior da cultura ocidental e de suas imposições arbitrárias (Haberkamp, 2000, p. 164) incita Nietzsche, a partir de Humano, demasiado humano, a acenar com a necessidade de uma nova análise dos pressupostos de consideração da ciência, em um direcionamento motivado pela evidenciação da origem moral dos pressupostos e das metas cognitivas da metafísica, da ciência e da religião. Neste momento é precisamente a perspectiva histórica que revela a pluralidade de interpretações humanas acerca do mundo e que assim inviabiliza não apenas a possibilidade de consideração da superioridade de uma delas, mas também demonstra quão ineficientes, para uma perspecti- 
va verdadeiramente científica, são o anseio e a pretensão hegemônica do saber. É neste sentido que pode ser lida a conhecida afirmação do segundo aforismo de Humano, demasiado humano, segundo a qual, "Tudo porém veio a ser; não há fatos eternos: assim como nenhuma verdade absoluta. - Desse modo, o filosofar histórico é doravante necessário e com ele a virtude da descrição" (KSA 2 § 2, p. 25).

A virtude da descrição torna-se assim um procedimento contrário à metafísica e à ciência em seu anseio por uma interpretação universal e definitiva da efetividade e do homem. Ela explicita o caráter não idealista da história e da psicologia concebida por Nietzsche, do ponto de vista de sua crítica da superestimação da consciência no processo cognoscitivo (Wotling, 1997, p. 3). Para Nietzsche, a pretensão de considerar a consciência e a racionalidade como fontes únicas de uma possível verdade acabou por circunscrever dogmaticamente a filosofia e a sua interpretação do saber em um mobilizar formal de conceitos vazios, no qual uma consideração efetiva do mundo não entra em questão, mas apenas a necessária não contradição lógica dos enunciados. Negados tais pressupostos, esse procedimento especulativo mostra-se problemático já em seus passos iniciais, haja vista que para Nietzsche tanto o "Eu" quanto a "coisa" não podem ser determinados, fundamentalmente porque não existem (MAM/HDH I § 19, p. 40). Conceitos de coisas são unicamente resultados da organização humana dos dados advindos da apreensão da multiplicidade do existente. Trata-se fundamentalmente de representações humanas não determinadas pela atividade lógico-racional consciente do homem que, com o decorrer do tempo e com o auxílio da linguagem, enquanto meio de ordenação das impressões sensórias por intermédio de metáforas e de convenções, confere a elas o caráter de unidade (KSA 1, p. 879). A Ideia de uma consciência decorre da percepção particular da função generalizante do intelecto na classificação da multiplicidade de sensações, de qualidades e de impulsos, que para Nietzsche remete o ser singular a uma autoconsideração enquanto indivíduo cognoscente em diferenciação ao mundo. Este, por conseguinte, não é constituído de unidades, mas passa a significar as delimitações fronteiriças do homem (M/A § 48).

Desse modo, contrariamente à interpretação cartesiana, a consciência (cogito) deixa, para Nietzsche de ser uma certeza imediata e de possuir a possibilidade de apreender de maneira direta e neutra os objetos a ela exteriores (Wotling, 1997, p. 5). Antes, ela é a última e mais tardia evolução do organismo, por isso a mais incompleta e fraca, da qual decorrem incontáveis conceitos falhos (FW/GC § 11). No que se refere à aspiração científica ocidental, o problema então consiste no fato de que a ela foi atribuído um valor superior, devido a ser com base nela que o homem "mostra o seu agir como ser racional sob o domínio das abstrações" e não sofre arrebatamen- 
tos por impressões imediatas. "Ele generaliza todas estas impressões primeiramente em descolorados e frios conceitos, para ligá-los (anknüpfen) como veículo de seu viver e agir" (KSA 1 p. 881).

Para Nietzsche, tal capacidade significa o primeiro passo do homem em seu processo de distanciamento da pura animalidade e em direção ao domínio sobre a natureza, que o leva à criação da civilização e da cultura. Assim como Freud, entretanto, no que se refere às pulsões (Gasser, 1997, p. 268), ele nega uma completa superação da animalidade pela racionalidade, devido à permanente atuação conflitante dos múltiplos impulsos e instintos ${ }^{5}$ em oposição a esta faculdade. Desse modo, ele compreende os sonhos como o protoestágio da racionalidade especulativa superior e meio de compreender estados temporalmente longínquos da cultura humana (MAM/HDH I § 13). A multiplicidade dos impulsos apresenta-se-lhe fundada em relações não determináveis, o que inviabiliza uma interpretação do homem como ser eminentemente racional. A racionalidade pode apenas de maneira precária e superficial sobrepor-se ao apelo pulsional (M/A § 109) e desse modo, mesmo o homem mais racional, "precisa de tempo em tempo, novamente da natureza, isto é, de sua ilógica atitude fundamental para com todas as coisas" (MAM/HDH I § 31).

A desconstrução da noção de Sujeito do conhecimento formulada pela metafísica remete Nietzsche ao âmbito da determinação dos valores morais, o que acaba por caracterizar seu filosofar histórico como um primeiro passo em direção a uma "Transvaloração de todos os valores" (EH/MAM/ HDH § 6). Com isso, Nietzsche pretende reabrir a discussão acerca do conhecimento em outro terreno, no qual a pressuposição de valores seja não negada mas entendida como perspectiva humana, pois o homem não pode existir sem uma "avaliação cognitiva sobre o valor do objectado" (MAM/

5 Muito embora em O nascimento da tragédia Nietzsche parta de uma interpretação dualista dos impulsos, representados pelo apolíneo e pelo dionisíaco, posteriormente, a partir de Humano, demasiado humano (§ 99, § 102), ele refere-se a uma interpretação mais ampla e plural destes. Mesmo a noção de impulso de conservação (Trieb der Erhaltung ou Erhaltungstrieb), formulada desde então - que é ampliada tanto em Aurora (§ 119) como em A gaia ciência (§ 1) pelo vetor teórico da vontade de poder -, respeita esta tendência; ao ser associada à ideia de multiplicidade e indeterminação associativa dos impulsos. Com efeito, para Nietzsche uma redução da complexidade das relações instintivo-pulsionais é considerada como interpretação moralizante (KSA 96 [123]), em oposição a uma interpretação efetiva, dinâmica e conflitante da existência, a qual revela que o ponto central da problemática referente aos impulsos e à interpretação da existência repousa não no determinismo ou na conservação, porém no devir e na expansão, ou seja, na indeterminação (Abel, 1998, p. 42). Neste sentido são dignas de nota, como fontes de influência desta concepção, além da crítica da noção de preservação e desencadeamento causal (Erhaltungs- und Auslösungskausalität) de Robert Meyer (idem, p. 39), o livro de W. Roux Der Kampf der Teile im Organismus (1881), que influenciou decisivamente a interpretação de Nietzsche sobre a ideia da vida como conflito (conf. Müller-Lauter, 1978, p. 199). 
HDH I § 32). Desse modo, as relações humanas com as coisas não são de modo algum primordial ou eminentemente racionais, do mesmo modo que nelas inicialmente não está em questão o conhecimento da suposta natureza intrínseca destas. Assim, com relação a elas, a predicação do objeto dáse de acordo com o interesse de nossas considerações (MAM/HDH I § 30), sendo a percepção sensorial a base dos juízos e do conhecimento humano sobre as coisas (Zichy, 2002, p. 39). Uma perspectiva científica que oblitera este caráter é falha, devido a seu desconhecimento do homem, e, precisamente por isso, ineficaz, não científica e, portanto, contraditória, se compreendida no contexto da cultura ocidental em seu anseio pela verdade. Em oposição a esta forma de consideração, Nietzsche enuncia um outro parâmetro para a atividade científica, segundo o qual a ambição de conhecer significa não mais o determinar de critérios para a consideração daquilo que existe, porém um primeiro e decisivo passo em direção à aceitação da multiplicidade e da dinamicidade da existência, ao qual se deve seguir a tentativa não dogmática de sua interpretação (M/A § 483).

Tal perspectiva permanece científica e em consonância com o próprio princípio originário da metafísica e da ciência no Ocidente, segundo o qual o autoconhecimento do homem apresenta-se para ambas como pressuposto fundamental da perspectiva científica. Neste sentido, uma consideração universal, porém, amoral do homem, efetuada com base na aceitação dos impulsos e que não almeja sua definição, pode ser entendida como "pensar impuro" ("unrein denken", MAM/HDH I § 33), porém simultaneamente como necessária à ciência. Ela adquire esta compreensão justamente por entender-se como inexata, mas também por afastar-se das tentativas formais de reformulação de pressupostos da própria metafísica que, pelo permanente desejo de fixidez e de imobilidade, são incompatíveis com a nova interpretação da efetividade, possibilitada precisamente pela relativização destes pressupostos valorativos, que, portanto, têm já suas possibilidades previamente restritas. Desse modo, a crítica da interpretação não histórica do Homem, deste tomado como aeterna veritas, acaba por possibilitar a compreensão segundo a qual ele "veio a ser e que também a Faculdade cognitiva (Erkenntnissvermögen) veio a ser" (MAM/HDH I § 2) e, portanto, aspirar por meio dela à obtenção de verdades definitivas acerca da efetividade apresenta-se para Nietzsche como falta de rigor científico (M/A § 270).

Relativizar o significado da racionalidade para o gênero humano consiste para Nietzsche em pressuposto basilar de seu projeto de promover mudanças nas categorias valorativas que durante séculos nortearam o pensamento ocidental. Tratar moralmente as questões da ciência e do conhecimento significa, por conseguinte, levantar a pergunta acerca da origem de suas valorações, que Nietzsche, como já anteriormente mencionado, encontra no socratismo e na espiritualidade cristã. Tal interpretação do racio- 
nalismo socrático encontra-se já em O nascimento da tragédia, em que este é indicado como responsável pelo banimento do dionisíaco da tragédia e pela consideração desta segundo pressupostos de clareza e inteligibilidade. Isso significa para Nietzsche a possibilidade de indicar claramente o momento de surgimento de uma nova forma de racionalidade, que, propagando-se para todo o mundo ocidental, teria determinado os pressupostos fundamentais não apenas da cientificidade, mas também da cultura. Tal ponto de vista é por ele preservado mesmo após o seu distanciamento da metafísica do artista e, por conseguinte, da pretensão de uma justificação artística da existência (GT/NT § 5). A crítica da racionalidade em Nietzsche refere-se decisivamente ao dogmatismo metafísico-racionalista e almeja consistir em uma instância crítica proba e atuante. Este é um aspecto decisivo para o entendimento da orientação filosófica do autor a partir de $\mathrm{Hu}$ mano, demasiado humano. Mesmo apresentada como científica, a filosofia de Nietzsche deve ser entendida como crítica também com relação à ciência, tal como evidencia a linha de desenvolvimento desta temática em $\mathrm{Au}$ rora e em A gaia ciência, fundada prioritariamente na problematização do predomínio hegemônico da metafísica (M/A § 197). Por intermédio dessa análise, Nietzsche visa, como já dito, a demonstrar a fragilidade científica e teórica da metafísica e assim indicar possibilidades de novos caminhos para o saber e para a cultura, o que, em seu modo de ver, acaba por possibilitar a revalorização de formas não científicas de consideração da efetividade, tal como a arte e a própria filosofia.

Em Humano, demasiado humano Nietzsche adota o ponto de vista de que aquilo que caracteriza a cientificidade é seu procedimento metodológico (MAM/HDH I § 635), e não a posse da verdade. É a metodologia que fornece às ciências naturais a constância e a demonstrabilidade das leis oriundas de generalizações inerentes à objetividade científica (FW/GC § 46). Ele, entretanto, recusa a existência de um único método possível para a ciência (M/A § 432), devido à adoção de um parâmetro não determinista de consideração da complexidade da efetividade. Assim compreendida, cientificidade torna-se um instrumento de consideração da realidade e deve ser considerada por intermédio de um remetimento aos impulsos (KSA 96 [64]) e tomada como desejo de conquista, de descobrimento e navegar aventuresco no mar que é o existente. Apartada da posse da verdade, deve também ser entendida como eterna imitação (MAM/HDH I § 136), como exercício de domínio da natureza e de uma moral que determina valores (M/A § 432). Com isso, Nietzsche intenta indicar que a ciência pensada rigorosamente não possui parâmetros restritivos e que o estabelecimento destes com vistas à determinação de seus interesses e metas não pode ser visto como procedimento científico, mas como moral. 
Foi a moralidade que, segundo ele, estabeleceu e manteve determinadas associações mantenedoras do status fundamentalmente positivo da ciência, como a relação entre valorações, determinação da verdade e felicidade humana, que Nietzsche identifica como presente na cultura ocidental desde os primórdios da metafísica. Isso deve significar, porém, não para a ciência, mas para o homem uma nova cadeia de possibilidades, da qual mesmo o risco de descobertas perigosas e lesivas ao gênero humano não são descartadas. Em Aurora, Nietzsche apresenta esta perspectiva como uma nova paixão pelo conhecimento que, consciente dos perigos que representa, mesmo assim o almeja (M/A § 429).

Essa nova paixão direciona a crítica de Nietzsche ao cristianismo, devido à histórica influência moral exercida pela religião sobre o saber. Este consiste, por conseguinte, em um dos temas centrais de Aurora e que possui posição também nuclear em sua concepção de ciência. O cristianismo para ele é responsável pela perpetuação da crença na relação intrínseca entre ciência e felicidade. União estabelecida no Ocidente pelo socratismo e perpetuada pelo cristianismo, ao tornar a verdade divina e associá-la a uma interpretação teleológica do saber e da história. Com o cristianismo estabelece-se no mundo romano uma nova faceta da interpretação da alma, a qual incontestavelmente faz-se presente de maneira decisiva no mundo ocidental (M/A § 72). Esta união é possível, segundo Nietzsche, devido a ambas possuírem um fator em comum, notadamente, a crença em um princípio fundamental, que Sócrates e Platão formularam como o bem, e o cristianismo como Deus (M/A § 58). Transposto para o domínio da ciência, ele fundamenta a crença em um mundo metafísico e em uma verdade incondicionada, cuja indelével presença Nietzsche identifica nos pressupostos basilares da ciência, tal como na ideia de ordenação causal da natureza e de seu finalismo teleológico. Dessa linha de continuidade resulta, segundo ele, uma indelével moralização da ciência, que então abandona sua justificativa inicial, a busca do conhecimento, e passa a almejar uma verdade definitiva e estável, o que determina para Nietzsche seu atuar, segundo pressupostos morais restritivos (M/A § 424).

O que é a verdade? - Quem não se deixa agradar com a conclusão a qual os crentes gostam de chegar: "a ciência não pode ser verdadeira, pois nega Deus". Por conseguinte ela não advém de Deus; logo ela não é verdadeira - pois Deus é a verdade. Não é a conclusão que contém o erro, mas no pressuposto, pois e se Deus não fosse a verdade? E se isso fosse realmente provado? Se ele fosse a vaidade, o desejo de poder, a impaciência, o medo, a ilusão extasiada ou aterrorizada dos homens? $(\mathrm{M} / \mathrm{A} \S 93)$ 
A moralização da ciência acaba por revelar aquele que Nietzsche demonstra como um dos pontos centrais de sua análise crítica da cientificidade, a saber: a subordinação do conhecimento à moral. A esse respeito, Nietzsche menciona em Aurora o realismo moral (moralische Realismus), cuja origem ele faz remontar a Sócrates e a Platão, e que se baseia na crença de que do conhecimento correto advêm ações corretas (M/A § 496). Este padrão interpretativo foi continuado pelo epicurismo, segundo o princípio de que "o virtuoso é mais feliz" (FW/GC § 12) e tomou decisivamente lugar no Ocidente, segundo a crença na saúde espiritual advinda do procedimento moral estrito (M/A § 202). Contrário a estas interpretações, Nietzsche visa a tornar evidente que sua crítica da ciência intenta fundamentalmente outra forma de radicalismo científico, que não se deve restringir à crença na cientificidade entendida como algo em si mesmo, pois para ele a clara semelhança de perspectivas entre moral religiosa e interpretação científica deixa claramente à mostra que jamais houve uma perspectiva científica pura e apartada da moral. Portanto, sua crítica da ciência é dirigida prioritariamente à exigência do estabelecimento de um maior senso crítico em seu interior, de um novo rigor impedindo que perspectivas morais restritivas confiram à ciência um valor por demais elevado (Zichy, 2002, p. 35), cujo efeito subsequente é, a seu ver, o retrocesso da cultura à barbárie moralizada.

A crítica da cientificidade concebida por Nietzsche, inserida no contexto pleno de sua transvaloração dos valores, desdobra-se em uma problematização das metas e finalidades da cultura e, portanto, não pode ser compreendida como uma forma de suicídio intelectual, ou seja, como uma tentativa de destruição ou desqualificação de todo procedimento racional. Muito embora ela possa ser caracterizada pela sua radical suspeição da racionalidade, ela objetiva com isso não o abandono desta, mas a desmistificação de sua autoridade conferida pela tradição racionalista. Sua crítica constrói-se com base na demonstração da contradição de seus pressupostos em relação à modernidade (M/A § 270), que busca tornar evidente a insustentabilidade da justificação essencialmente moral da ciência em uma cultura que se caracteriza e festeja seu estabelecimento a partir de um afastamento em relação ao mitológico. ${ }^{6}$ Evidenciar que tal separação jamais ocorreu (KSA 96 [252]), que o discurso científico ainda se aproxima das narrativas míticas que ele refuta, consiste para Nietzsche em um passo necessário para sua tentativa de atualização da ciência e de sua melhor inserção no contexto da nova compreensão do mundo, que o próprio procedimento metodológico da ciência revela.

6 Ou como Mittasch, a partir da sistematização de antigas cosmologias (Mittasch, 1953, p. 216). 
Sendo assim, a cientificidade concebida por Nietzsche não pode ser entendida como cética, pois preserva o princípio de uma rigorosa veracidade, porém não mais de modo definitivo (FW/GC § 51). Esta passa a ser por ele entendida como critério norteador da atividade científica, baseada no método (MAM/HDH I § 278), na aceitação das contradições, enquanto forma de poder exprimir a dinâmica do existente. Nesse sentido, a meta por ele visada é mesmo a superação do pessimismo evidenciado no Ocidente resultado da inalcansabilidade das metas estabelecidas pela racionalidade científica e pela moral a ela inerente desde seus primórdios (MAM/HDH I 128). Esta separação é possível não por meio da promessa de solução das problemáticas ancestrais da metafísica, mas da demonstração do erro intrínseco a elas, tal como na crença na relação causal entre conhecimento verdadeiro e felicidade (FW/GC § 37).

Para Nietzsche, a causa da desilusão cultural no Ocidente encontra-se precisamente na contradição decorrente da fusão entre platonismo e cristianismo (KSA 96 [392]), que remete a cultura a um pragmatismo dogmatizante não exequível. Na modernidade, após mais de 2 mil anos de tirania de ambas as perspectivas, tal projeto demonstra seu esgotamento em todos os domínios, o que pode ser evidenciado pela completa discrepância entre o mundo representado pelo racionalismo e pelo moralismo religioso (MAM/ HDH I § 110). Este é uma evidência que um olhar amoral passa a descobrir com base na aceitação da diversidade de povos, culturas e a constante alteração das compreensões da efetividade. A isso é associada por Nietzsche a outra e muito mais complexa compreensão do homem, baseada em sua constituição fisiológica, que implica a aceitação da multiplicidade pulsional e da animalidade, que tanto o cristianismo como a ciência insistem em desmerecer e desprezar (Kang, 2003, p. 32). Desse modo, segundo uma nova forma de probidade intelectual que demonstra o antagonismo entre ciência e moral (Giacoia, 1997, p. 105), Nietzsche visa esclarecer os âmbitos próprios para a atuação de ambas. A crítica do cristianismo dá-se então fundamentalmente segundo uma perspectiva científica que compreende os antigos critérios avaliativos como obsoletos e inatuais.

A consideração da discrepância entre cristianismo e saber baseia-se, como anteriormente mencionado, na constatação de uma hegemonia científica que, para Nietzsche, caracteriza a cultura ocidental e que, mesmo tendo como fonte originária a metafísica, acaba por inviabilizá-la. Como pontos nevrálgicos deste conflito, Nietzsche indica dois focos prioritários e intimamente relacionados com a ciência: o domínio da arte e o da moral. Com relação à primeira ele detecta a estagnação da criação artística e o recurso a princípios arcaicos de justificação desta, tais como genialidade e inspiração. No que concerne à moral, sinaliza a permanência de uma obsoleta forma de fundamentação pia de formas universais de consideração, so- 
bre as quais se pode muito mais facilmente falar da perpetuação da barbárie (MAM/HDH I § 285), que da possibilidade de estabelecimento de um mundo moralizado, do qual Nietzsche discorda (FW/GC § 3).

Adotar um olhar científico significa, portanto, aproximar-se da efetividade, aceitá-la em sua variabilidade e multiplicidade, em lugar de tentar refutá-la devido à impossibilidade de sua definitiva compreensão. Significa alegrar-se com a nova interpretação da efetividade tal qual ela pode ser percebida (M/A § 244), e não a negar por sua inadequação a padrões pré-definidos. Trata-se de um novo mar, de um novo horizonte cheio de novos, porém, igualmente perigosos caminhos, pois a cientificidade também pode nos ser nociva, descoberta como uma grande portadora de dores (grosse schmerzbringerin, FW/GC § 12). Essa é a perspectiva do espírito livre, que vê na ciência, a partir da desmistificadora interpretação do homem e de seu agir como similar ao do animal na natureza, em sua vencedora sabedoria (siegereiche Weisheit), fundamentalmente um meio de exercício de poder e domínio (M/A § 201). Desse modo, a ciência concebida por Nietzsche apresenta-se como resultado de sua interpretação interna dos valores fundantes da cultura ocidental, e não como resultado da formulação de um conceito prescritivo (KSA 1125 [307]). Ela é, a partir de Humano, demasiado humano, resultado de sua aproximação das pesquisas físicas e biológicas de seu tempo, das pesquisas de Eduard von Hartmann, da física de Boscovich, Zöllner, Caspari, Liebmann e Robert Mayer e da constatação da discrepância dos resultados destas e das interpretações religiosa e metafísica do mundo (Abel, 1998, p. 46).

A Gaia Ciência é, com efeito, a alternativa de Nietzsche para a solução do impasse gerado pelo conflito entre ciência e moralidade no Ocidente. Ela significa a exigência de uma busca rigorosa pelo conhecimento associada à sua relativização, a partir da explicitação do conteúdo moral e perspectivístico de toda forma de aspiração ao saber. Trata-se de uma reformulação radical da ideia de cientificidade, que se liberta do controle absoluto da moral, precisamente por se compreender e apresentar como produtora de valores. O conceito de verdade é então decisivamente relacionado ao de valor e à relatividade deste, de modo que, justamente por ser produtora de valores e não de verdades absolutas, esta nova concepção de ciência pode ser afirmada como perspectiva científica proba. Ela é o resultado da compreensão de que mesmo o mais rigoroso procedimento científico deve ser interpretado como atividade humana (FW/GC § 112) e, portanto, deve ser reduzido a uma aferição de valor às coisas.

Tal postura intelectual deve ser compreendida com base em sua diferenciação da probidade cristã, cujos dogmas e recursos à autoridade moral (KSA 1125 [447]) são então descartados enquanto atitudes não científicas (M/A § 84). Relacionada à ciência, probidade intelectual (intellectuelle 
Redlichkeit) para Nietzsche significa uma extrema exigência de clareza e exatidão que, cônscia de seu alcance como atitude descritivo-representativa e não determinista (FW/GC § 112), mesmo assim é necessariamente pautada pela exigência do rigor e (idem § 293), tal como a matemática, situa-se como fonte de uma relação mais refinada e rigorosa com as coisas:

Matemática - nós queremos introduzir o refinamento e o rigor da matemática em todas as ciências, até onde isso for possível, não na crença de que por essa via conheceremos as coisas, mas para assim determinar nossa relação humana com as coisas. A matemática é apenas um meio para o conhecimento humano geral e final. (FW/GC § 246)

Por outro lado, entretanto, a nova probidade intelectual integra também a arte ao conhecimento, pois supera a polarização entre aparência e essência, entre fenômeno e coisa-em-si da metafísica tradicional, e pode tomar a segunda como modelo plural de interpretação e representação do mundo. A arte ganha nova importância não por propiciar uma nova via para o conhecimento da realidade, pelo contrário, ela é reavaliada pela possível força de representação que gera e que então pode atuar em dois âmbitos prioritário: a) enquanto meio de consolação do temor causado pela refutação dos modelos morais de consideração do mundo, a partir da sedução da criação novamente tornada possível e, desse modo, b) como princípio afirmativo e embelezador da indeterminabilidade e riqueza de possibilidades da efetividade (FW/GC § 54). Ambos os aspectos associam-se indissoluvelmente à perspectiva científica de Nietzsche no período. No primeiro caso, a arte é interpretada como antídoto para o pessimismo científico e cultural, que o autor interpreta nas filosofias de Kant e Schopenhauer. No segundo, ela é pensada como estimulante do desejo de conhecer, que então, motivado pelo impulso aventuresco, tem diante de si um novo e infinito mundo de possibilidades a ser explorado.

A alegre ciência é então o resultado dessa nova perspectiva. Ela aglutina ciência e arte e é concebida como uma nova possibilidade aberta pelo vazio causado pela supressão do conceito absoluto de verdade e da morte de Deus (FW/GC § 125), que Nietzsche apresenta simultaneamente enquanto alegria trágica, mas também como paródia de sua seriedade (FW/GC Prefácio § 1).

A Gaia Ciência é trágica por caracterizar-se como amor fati, ou seja, não apenas por aceitar os novos perigos que o saber proporciona, mas por querer experimentá-los, criando para esta nova compreensão da realidade uma imagem afirmativa (FW/GC § 276). 
Seu caráter paródico com relação às formas tradicionais de cientificidade também é uma forma de oposição à metafísica e à moral, expresso pelo riso sarcástico e contrário a toda falsa seriedade dogmática. O que a ciência busca na arte é a força da representação estética, que, mesmo segundo uma nova e mais acurada compreensão (FW/GC § 87), deve remeter o homem e a cultura à criação e à experimentação (FW/GC § 58, § 60). Com a arte, a ciência pode aprender as vantagens de não perder a liberdade sobre as coisas, do poder de ficar acima da moral e então suportar a diversidade de estados e momentos da existência (FW/GC § 107), pois o mundo não pode ser restrito a formas de consideração moralmente impostas (FW/ GC § 109). Trata-se, portanto, de um saber liberto dos antigos dogmas, rigoroso e lúcido em seu trato e representação da efetividade, que não necessita mais ser determinada. Assim, ele justifica-se fundamentalmente pela energia criativa que libera e não necessita de um ponto de chegada, compreendido então como erro.

Excelsior! - Tu nunca mais rezarás, nunca mais adorarás, nunca mais repousarás em infinita confiança - tu te proíbes a parar diante de uma sabedoria última, de uma bondade última, de um último poder e assim desarrear os teus pensamentos. (FW/GC § 285)

A crítica à dependência da cultura ocidental da moralidade cristã, expressa na citação inicial deste artigo, deve ser compreendida como um dos pressupostos da crítica de Nietzsche à absolutização de uma moral (M/A $\S 164)$, que, vinda do Oriente, acaba por determinar os valores fundantes da cultura ocidental, com a qual, em sentido estrito, ela não se coaduna. Desse modo, refletindo radicalmente com respeito a ambas, o autor tenta demonstrar que uma ciência regida por uma moral absoluta não pode ser compreendida como ciência, do mesmo modo que uma moralidade com perspectivas absolutas não se pode coadunar com aspiração proba ao saber. Com A Gaia Ciência, o autor fecha um ciclo iniciado com Humano, demasiado humano, no qual por meio de uma crítica desmistificadora, tenta demonstrar a forma decisiva da inserção de pressupostos morais na ciência em favor desta.

A crítica da religião cristã deve, por conseguinte, ser compreendida de forma análoga. Ao acentuar a força da crença na veracidade da interpretação religiosa do mundo e o modo pelo qual, a partir desta, dão-se a limitação da ciência e a construção da esperança de uma possível transformação do mundo pela fé (KSA 8, 23 [185]), Nietzsche tenta demonstrar não apenas a moralização da cientificidade no Ocidente, mas simultaneamente a despotencialização da religiosidade transposta para um Terrain ao qual os seus pressupostos não se mostram adequados. É nesse contexto que deve ser entendido o anúncio da morte de deus e da necessidade de transvaloração 
de todos os valores (Marton, 2000, p. 91), pois a verdade não deseja nenhum Deus consigo, e a crença na verdade inicia-se com a dúvida com respeito a todas as verdades pias. Trata-se não de uma determinação, mas de uma constatação de que a crença no Deus cristão decresce, em uma cultura direcionada à busca do saber e com o qual ela não pode concorrer ou limitar, restando-lhe como última alternativa ignorar seus resultados ou interpretálos como pecado (M/A § 89).

Os efeitos dessa associação são para Nietzsche evidentes, quer na religião, quer na filosofia, e caracterizam aquilo que ele destaca como o cansaço do homem europeu na modernidade, em outras palavras, como pessimismo ante o malogro dos antigos ideais. Este se estabelece precisamente pela compreensão da falibilidade das interpretações humanas acerca do mundo.

Nós sabemos que o mundo em que vivemos não é divino, amoral [unmoralische] e "inumano" [unmenschlich], - nós mentimos e falseamos a nós mesmos, por um tempo longuíssimo, porém isso devido ao nosso desejo e vontade de veneração, isso é, devido a uma necessidade. Pois o homem é um animal que venera! Mas ele é também um animal desconfiado: e que o mundo não possui o valor que nós acreditávamos, é aproximadamente aquilo de mais seguro, do qual se apoderou a nossa desconfiança. Tanta desconfiança, tanta filosofia. Nós somos cuidadosos em dizer que o mundo tem um valor menor: parece-nos hoje mesmo risível quando o homem pretende inventar [erfinden] valores que devessem exceder os do mundo efetivo. Exatamente com isso retornamos a um notável equívoco da vaidade e da desrazão humana, que longamente ainda não foi reconhecido enquanto tal. (FW/GC § 346)

O pessimismo europeu, tal qual Nietzsche menciona no aforismo acima citado, é o resultado das falsas venerações da cultura ocidental, tanto morais quanto científicas (Zichy, 2002, p. 80). Ele é a depreciação destas venerações e do próprio homem, que no aforismo seguinte ele indica como resultado do conflito entre religião e ciência positiva, como "cansaço, fatalismo, decepção e medo de novas decepções" (FW/GC § 347).

Não se trata, portanto, de querer o banimento quer da religião, quer da metafísica da cultura ocidental - pois o homem é um animal que venera! E por isso necessita delas. Mas necessário é compreender claramente seus domínios de atuação. Nesse sentido, Nietzsche é claro ao acentuar, já em Humano, demasiado humano e segundo uma nova interpretação do homem e da cultura, os ganhos desta múltipla, criativa e dinâmica forma de tolerar agonisticamente e assimilar perspectivas distintas, mesmo da religião e da metafísica (MAM/HDH I § 278). Com vistas a uma ciência que necessita então adequar-se à nova dinamicidade da efetividade, sem aspirar a um porto de chegada para seus esforços, ocorre mesmo a necessidade de discursos contrários, que fomentem a disputa por meio de novos argumentos e perspectivas e, desse modo, impeçam a estagnação da ciência. 
Contra a tirania do verdadeiro. - mesmo que nós fossemos loucos o suficiente para tomar todas as nossas opiniões por verdadeiras, nós não iríamos querer que elas existissem sozinhas -: eu não sabia que a hegemonia [Alleinherschaft] e onipotência [Allmacht] da verdade era algo de desejoso, para mim já bastava, que ela possuísse um grande poder. Mas ela necessita saber lutar, sofrer oposição e necessitase, no não verdadeiro [Unwahren], separar-se dela ocasionalmente, para então poder dela se recuperar. Caso contrário ela se tornará tediosa, sem força e gosto, e fará o mesmo conosco. (M/A § 507)

BARROS, Roberto. Scientific critique and interpretative models in Nietzsche. Trans/ Form/Ação. (São Paulo), v.31(2), 2008, p. 61-77.

- ABSTRACT: From the denounce of the contradictory presence of dogmatic moral presuppositions in the formulation of scientific activity principles, Nietzsche conceives another notion of science compatible with the hegemonic option for knowledge, which he recognizes as present in occidental culture. This article intends to discuss on which parameters Nietzsche, in the intermediary period of his philosophical production, proposes his interpretation of occidental science and formulates a demystifying critique of it.

- KEYWORDS: science; effectiveness; reality; history; morality.

\section{Referências bibliográficas}

ABEL, Günter. Nietzsche. Die Dynamik der Willen zur Macht und die ewigen Wiederkehr. Berlim/Nova York: Walter de Gruyter, 1998.

FIGAL, Günter. Nietzsche. Eine philosophische Einführung. Stuttgart: Reclam, 2001.

GASSER, Reinhard. Nietzsche und Freud. Berlim: Walter de Gruyter, 1997 (Monographien und Texte zur Nietzsche-Forschung; Band 38).

GIACOIA JÚNIOR, Oswaldo. Notas sobre o tema da auto-supressão da moral. In: Labirintos da alma. Nietzsche e a auto-supressão da moral. Campinas (SP): Editora da Unicamp, 1997, p. 127-38.

HABERKAMP, Günter. Triebgeschehen und Wille zur Macht. Nietzsche - zwischen Philosophie und Psychologie. Würzburg: Königshausen \& Neumann, 2000 (Nietzsche in der Diskussion).

HELLER, Peter. "Von der ersten und letzten Dinge". Berlim: Walter de Gruyter, 1972. KANG, Yong-Soo. Nietzsches Kulturphilosophie. Würzburg: Königshausen \& Neumann, 2003.

MARQUES, António. A filosofia perspectivista de Nietzsche. São Paulo: Unijuí, 2003.

MARTON, Scarlett. O eterno retorno do mesmo. Tese cosmológica ou imperativo ético? In: Extravagâncias. Ensaios sobre a filosofia de Nietzsche. São Paulo: Unijuí, 2000, p. 67-94. 
MITTASCH, ALWIN. Friedrich Nietzsche als Naturphilosoph. Stuttgart: Alfred Kröner Verlag, 1953.

MÜLLER-LAUTER, W. Der Organismus als innerer Kampf. Der Einfluss von Wilhelm Roux auf Friedrich Nietzsche. Nietzsche-Studien, v. 7, n. 7, Berlim, 1978, p. 97-140.

NIETZSCHE, Friedrich Wilhelm. Sämtliche Werke. Kritische Gesamtausgabe (KGW). G. Colli \& M. Montinari (eds.). Berlim/Nova York: De Gruyte/DTV 1980.

Obras incompletas. Trad. e notas de Rubens Rodrigues Torres Filho 3. ed. São Paulo: Abril Cultural, 1983 (Coleção Os Pensadores).

WOTLING, Patrick. Der Weg zu den Grundproblemen. Nietzsche-Studien, v. 26, n. 26, Berlim, 1997, p. 1-33.

ZICHY, Michael. “...aber die Wahrheit ist sehr, sehr complizirt”. Der Begriff der Wahrheit im mittleren Werk Friedrich Nietzsches. Berlim: VWF, 2002. 